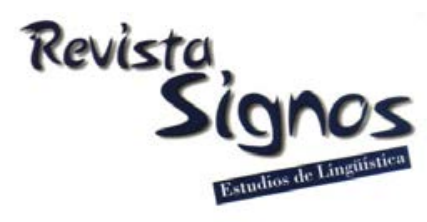

\title{
EDITORIAL
}

\section{Procesos de lectura y escritura en el mundo contemporáneo de lengua española}

Los estudios compilados en este volumen dan cuenta de una prolífica diversidad de aproximaciones coexistentes y revelan, al mismo tiempo, el magnífico estado actual de las investigaciones en procesos de lectura y escritura en el mundo de los textos escritos en español. Los once artículos reúnen a un grupo de treinta investigadores provenientes de un número significativo de universidades que, en su conjunto, alcanza a ocho países: Alemania, Argentina, España, Estados Unidos, Brasil, Colombia, Chile y México.

La heterogeneidad se convierte así en una de las riquezas de este número monográfico y en un valor que destacamos para la panorámica que se buscaba ofrecer en este volumen especial. No redundaremos aquí en la relevancia de la lengua escrita ni en los requerimientos actuales de estrategias que apoyen la formación de lectores y escritores eficientes de géneros discursivos diversos. Dejo el espacio para que cada uno de los once estudios aporte su perspectiva y defienda el lugar desde el cual se ha construido su nicho científico. Baste con señalar, eso sí, que la sola inclusión, por primera vez en su historia, de un volumen de esta envergadura en nuestra Revista Signos. Estudios de Lingüistica -la cual está cercana a cumplir cincuenta años de existencia (1967-2017) - es una potente señal de la centralidad que los procesos de comprensión y producción de textos escritos en español ocupan en el mundo contemporáneo. 
La rica diversidad de enfoques de investigación que estos once estudios aportan constituye solo una muestra de los posibles caminos actuales que los investigadores ponen en ejercicio para enfrentar sus desafíos y preguntas de investigación. No obstante ello, son ejemplos singulares de lo que acontece en la actualidad en lengua española. Del mismo modo, cada uno de ellos también se erigen en sí mismo como modelo metodológico de investigación que puede motivar y orientar a jóvenes investigadores y servir de base para estudios en diversos niveles, tales como en pre y postgrado, y en contextos de tipo académico y profesional. En este sentido, cada artículo aporta un marco conceptual particular y unas opciones metodológicas que, en su conjunto, ofrecen alternativas coherentes de investigación, pero -sobre todoaportan hallazgos empíricos que permiten avanzar en las fronteras del conocimiento científico.

De modo más específico, los trabajos aquí compilados construyen, entre todos, un abanico de dimensiones en lectura y escritura que van desde reflexiones teóricas críticas, a estudios descriptivos empíricos de orden cualitativo y cuantitativo (ya sea a nivel de ejemplos ilustrativos o con sustento en amplios corpus de textos), pasando por intervenciones didácticas en aula, hasta estudios experimentales de alcance explicativo con apoyo de tecnologías computacionales de última generación (eye tracker). Como se aprecia, esta heterogeneidad no debe sorprender, sino que -como ya decíamos- constituye el gran valor de la diversidad contemporánea de líneas de investigación y de métodos de exploración.

En cuanto a procedimientos editoriales, he seguido los principios de transparencia para la evaluación ciega de pares expertos de los trabajos aquí publicados. Así, el carácter de número especial monográfico no tranza con los procedimientos regulares de rigor evaluativo que se aplican a todo artículo que se somete al proceso editorial de evaluación en nuestra revista.

Por último, expreso mis agradecimientos a los treinta escritores que colaboraron en esta empresa monográfica y que recibieron con entusiasmo la invitación y, a la vez, el desafío de construir en conjunto este volumen señero. Sus esfuerzos y trabajos espero- los hayan dejado satisfechos. Estoy seguro de que más de alguno pensó en desistir de continuar adelante cuando el camino de los procesos de evaluación pudieron haberse tornado -por momentos- muy demandantes o hasta extremadamente invasivos. Afortunadamente, la mayoría no se rindió y logramos, en plazos relativamente breves, artículos de alta calidad.

También agradezco al grupo de evaluadores anónimos, sin cuya labor oportuna y certera no habríamos logrado cumplir con los estándares regulares de nuestra revista. Me consta que todos ustedes hicieron esfuerzos tremendos por acortar los plazos acostumbrados y aportar su valiosa revisión en tiempos breves. 
Como toda empresa humana, el cierre de un proceso gratificante nos alegra enormemente, aunque también nos deja algo de nostalgia. Espero, entonces, que este volumen cumpla su objetivo y que los lectores interesados encuentren en estas páginas reflexiones teóricas y hallazgos empíricos que les aporten y los motiven a seguir investigando en los fundamentales procesos de comprensión y producción de textos escritos.

\section{Dr. Giovanni Parodi}

EDITOR EN JEFE

Viña del Mar, Chile, octubre de 2016. 